\title{
Shift in size of bumblebee queens over the last century
}

\author{
Maxence Gérard $^{1}$ (D) | Baptiste Martinet ${ }^{1}$ | Kevin Maebe ${ }^{2}$ | Leon Marshall ${ }^{3,4}$ | \\ Guy Smagghe $^{2}$ | Nicolas J. Vereecken ${ }^{3}$ | Sarah Vray ${ }^{1,5}$ | Pierre Rasmont ${ }^{1}$ | \\ Denis Michez ${ }^{1}$
}

${ }^{1}$ Laboratoire de Zoologie, Research Institute of Biosciences, University of Mons, Mons, Belgium

${ }^{2}$ Department Plants and Crops, Faculty of Bioscience Engineering, Ghent University, Ghent, Belgium

${ }^{3}$ Agroecology Lab, Université libre de Bruxelles (ULB), Brussels, Belgium

${ }^{4}$ Naturalis Biodiversity Center, Leiden, The Netherlands

${ }^{5}$ Environmental Research and Innovation Department, Luxembourg Institute of Science and Technology, Belvaux, Luxembourg

\section{Correspondence}

Maxence Gérard, Laboratoire de Zoologie, Research Institute of Biosciences, University of Mons, Place du Parc 23, 7000 Mons, Belgium.

Email: Maxence.gerard@umons.ac.be

\section{Funding information}

Fonds de la Recherche Scientifique - FNRS; Research Foundation-Flanders (FWO) under EOS Project named CLIPS, Grant/ Award Number: 3094785; Belgian Science Policy; Research Foundation-Flanders (FWO research project), Grant/Award Number: 3G042618; Fonds pour la Recherche dans I'Industrie et l'Agriculture

\begin{abstract}
Species can respond differently when facing environmental changes, such as by shifting their geographical ranges or through plastic or adaptive modifications to new environmental conditions. Phenotypic modifications related to environmental factors have been mainly explored along latitudinal gradients, but they are relatively understudied through time despite their importance for key ecological interactions. Here we hypothesize that the average bumblebee queen body size has changed in Belgium during the last century. Based on historical and contemporary databases, we first tested if queen body sizes changed during the last century at the intraspecific level among four common bumblebee species and if it could be linked to global warming and/or habitat fragmentation as well as by the replacement by individuals from new populations. Then, we assessed body size changes at the community level, among 22 species, taking into account species population trends (i.e. increasing, stable or decreasing relative abundance). Our results show that the average queen body size of all four bumblebee species increased over the last century. This size increase was significantly correlated to global warming and habitat fragmentation, but not explained by changes in the population genetic structure (i.e. colonization). At the community level, species with stable or increasing relative abundance tend to be larger than declining species. Contrary to theoretical expectations from Bergmann's rule (i.e. increasing body size in colder climates), temperature does not seem to be the main driver of bumblebee body size during the last century as we observed the opposite body size trend. However, agricultural intensification and habitat fragmentation could be alternative mechanisms that shape body size clines. This study stresses the importance of considering alternative global change factors when assessing body size change.
\end{abstract}

\section{KEYWORDS}

Bergmann's rule, body size, bumblebees, genetic structure, global change, habitat fragmentation 


\section{1 | INTRODUCTION}

Biodiversity is currently undergoing major declines as a result of global changes induced by humans (Dirzo et al., 2014). Populations under threat have three main outcomes: (a) migrate by shifting their geographical range to suitable habitats; (b) persist in the same place through genetic, plastic and/or behavioural adaptation; or (c) become extinct (McCarty, 2001). Species communities can also be negatively impacted by spatial or temporal mismatches of key interactions (e.g. seed dispersal or pollination; Schleuning et al., 2016) and by the loss of functional traits (e.g. Strahan, Sanchez Meador, Huffman, \& Laughlin, 2016). While shifts of distribution (e.g. Hickling, Roy, Hill, Fox, \& Thomas, 2006) and phenology (e.g. Ford, Harrington, Bansal, Gould, \& Clair, 2016) are well studied at both the species and community level, there is much less information about the phenotypical consequences of global environmental changes.

Body size is a key element of the phenotype for species survival as it is related to many aspects of individual fitness such as reproduction (Werner \& Griebeler, 2011), life span (Peters, 1983), foraging range (e.g. Greenleaf, Williams, Winfree, \& Kremen, 2007) and home range size (e.g. Peters, 1983). Like all phenotypical traits, body size is affected by genetic and environmental factors through complex cellular (e.g. growth rate, cell size, cell number; e.g. Azevedo, French, \& Partridge, 2002) and molecular processes (e.g. hormones secretion; Nijhout, 2003). A relationship between a shift in body sizes and global changes could therefore be explained by the modification of environmental factors inducing plastic responses (i.e. phenotypic plasticity, e.g. Grether, 2005) or selective pressures (i.e. natural selection, e.g. McCabe, French, \& Partridge, 1997). Moreover, a shift in body size could also be related to (partial) replacement by individuals from new populations with different body size (Romano \& Ficetola, 2010). While phenotypic modifications induced by plastic responses (adaptive, neutral or nonadaptive) are nonheritable and reversible (Fusco \& Minelli, 2010), body size changes driven by selection results in permanent changes to the genotype (Gienapp, Teplitsky, Alho, Mills, \& Merila, 2008). Disentangling these plastic and selective phenotypic modifications and relating these to environmental change has been a major focus for evolutionary biologists (Gienapp et al., 2008). However, studies highlighting microevolutionary changes of body size clines in the context of quantitative genetics are scarce when it comes to invertebrates (e.g. Brans, Govaert, et al., 2017; Brans, Jansen, et al., 2017; Huey, Gilchrist, Carlson, Berrigan, \& Serra, 2000; Umina, Weeks, Kearney, McKechnie, \& Hoffmann, 2005). Overall, no matter the mechanism driving body size modification (i.e. replacement by individuals from new populations, plasticity or selection), a consistent increase or decrease in body size at both intra- and interspecific levels in the same areas over time would provide strong evidence of a significant impact of global change on the phenotype of a community.

Many factors of global change have been found to strongly impact body size. The average body size is generally expected to decrease in response to higher temperature, which has been proposed as a universal response to global warming (Classen, Steffan-Dewenter,
Kindeketa, \& Peters, 2017; Gardner, Peters, Kearney, Joseph, \& Heinsohn, 2011; Millien et al., 2006). It is also known that habitat modification (i.e. fragmentation, urbanization) or a shift of diet can modify body size clines (Beasley, Penick, Boateng, Menninger, \& Dunn, 2018; Merckx, Kaiser, \& Van Dyck, 2018; Merckx, Souffreau, et al., 2018; Virgos et al., 2011; Warzecha, Diekötter, Wolters, \& Jauker, 2016), though these factors are much less studied. Larger individuals may be favoured in fragmented habitats as they can reach isolated patches more easily due to their higher mobility (e.g. Warzecha et al., 2016) even if once habitat fragmentation is particularly high, smaller and less mobile species may also be favoured (Merckx, Kaiser, et al., 2018; Merckx, Souffreau, et al., 2018). Exposure to pesticides can produce a similar effect as larger individuals are often more resistant to the same dose compared to smaller individuals (e.g. Whiterhorn et al., 2018). Conversely, small species can be favoured in habitats with limited resources (e.g. Müller et al., 2006; Scheper et al., 2014; but see Merckx, Kaiser, et al., 2018; Merckx, Souffreau, et al., 2018). McNab (2010) called this trend the 'resource rule'.

Very few studies have explored the patterns of size modification in response to global change in invertebrates, even though they make up the majority of the diversity of animal life on Earth (The World Conservation Union, 2014). Among invertebrates, bees are valuable pollinators of major crops and wild plants (Klein et al., 2007). They are experiencing strong population declines due to global threats including global warming, intensification of agricultural practices and habitat degradation (Goulson, Nicholls, Botías, \& Rotheray, 2015; Kerr et al., 2015; Ollerton, 2018), all factors that potentially also impact their body size. A few studies have documented body size variation in bees along latitude and in various experimental conditions (e.g. Classen et al., 2017; Gérard, Michez, et al., 2018; Gérard, Vanderplanck, et al., 2018; Hawkins, 1995; Peat, Darvill, Ellis, \& Goulson, 2005; Ramirez-Delgado, Sanabria-Urban, Serrano-Meneses, \& Cueva Del Castillo, 2016). While Bergmann's rule (i.e. larger individuals are found in colder climates) seems to apply in many bee taxa (e.g. Hawkins, 1995; Peters, Peisker, SteffanDewenter, \& Hoiss, 2016; Gérard, Vanderplanck, et al., 2018; but see Dellicour et al., 2017), bumblebees could be a notable exception and may follow converse Bergmann's rule, maybe because of the 'season length effect' (i.e. larger resource availability in favourable regions where season length is longer, Gérard, Vanderplanck, et al., 2018; Ramirez-Delgado et al., 2016; but see Scriven, Whitehorm, Goulson, \& Tinsley, 2016). However, nothing is known about the impact of global environmental changes on bee body size in field conditions.

Nearly 400 species of wild bees have been recorded in Belgium (Rasmont et al., 2017). We considered the genus Bombus (i.e. bumblebees) only as they include dominant and abundant species in most of the Belgian bee communities (Rasmont et al., 2015). Among wild bees, bumblebees are an exception in many ways: they are social, endotherms and several species are able to live in particularly cold regions (Rasmont et al., 2015). Bumblebees are also subject to the attention of many naturalists because of their bright colours and their relatively large size. Bumblebees are therefore abundant in historical and recent museum collections. Based 
on museum collections and recent bumblebee queens collected in Belgium, we first assessed the relationship between mean bumblebee queen body size and time (year by year) at the intraspecific level within four common species (i.e. Bombus hortorum, Bombus lapidarius, Bombus pascuorum and Bombus pratorum) during the last century. We then tested if intraspecific variation in body sizes could be related to (a) global warming and (b) habitat fragmentation in Belgium. We hypothesized that: (a) body size would decrease during this time period if global warming is the main driver of body size clines; (b) body size would increase if habitat fragmentation is the main driver of body size clines. We additionally analysed the genetic structure of Belgian bumblebee populations through the last century to test potential replacement by individuals from new populations which could also impact body size clines in both ways. We finally tested if the intraspecific pattern of body size shifts could be extended to the community level by relating the relative population trends of 22 Belgian bumblebee species to their body size. We hypothesized that the smallest species were more prone to decline in abundance in more fragmented habitat.

\section{2 | MATERIAL AND METHODS}

\section{1 | Global warming and habitat fragmentation in Belgium}

For the intraspecific analysis, we gathered data on global warming and habitat fragmentation to assess their correlation with body size clines over the last century in Belgium. The mean annual temperature of each year was collected from the weather station of Uccle (Belgium) which has recorded temperature in Belgium since 1880. Historical land use/land cover (LULC) maps for the whole of Belgium from 1900 to 2010 are not available at present. Therefore, to estimate fragmentation changes over the last century in Belgium we used historic reconstruction maps for Europe (Fuchs, Herold, Verburg, Clevers, \& Eberle, 2015). These maps represent a modelled reconstruction of LULC in Europe per decade from 1900 until 2010 using a combination of historical LULC data sources and a modelling approach called Historic Land Dynamics Assessment or HILDA (Fuchs, Herold, Verburg, \& Clevers, 2013; Fuchs et al., 2015). Six LULC classes are available in the HILDA maps at a $1 \mathrm{~km} \times 1 \mathrm{~km}$ resolution, and include forests, grasslands, cultivated land, human settlements, water and other. We clipped the HILDA maps to the extent of Belgium for each decade and calculated two metrics of fragmentation: patch density and edge density. All calculations were conducted in Rstatistics using the 'landscapemetrics' package (version 1.1; Hesselbarth, Sciaini, Nowosad, \& Hanss, 2019). Patch density is a measure of the number of patches of different LULC at the Belgian scale, the value represents this per 100 ha (McGarigal, Cushman, \& Ene, 2012). Edge density measures fragmentation as the total number of edges per 100 ha at the Belgian scale, edges being defined as the length of the boundaries between two different LULC classes (McGarigal et al., 2012).
We assessed how mean annual temperature, patch density and edge density (i.e. dependent variable) varied in Belgium during the last century using generalized linear models with time as the independent variable.

\section{2 | Body size measurement}

We used intertegular distance (i.e. distance in millimetres between the two insertion points of the wings; ITD) as a proxy of the body size (Cane, 1987). ITD was measured using a Facom 150 mm digital calliper (France, Morangis). To evaluate intraspecific variation of body size, we selected a total of 895 bumblebee queens collected between 1902 and 2018 (Table S1): 186 queens of B. hortorum, 290 queens of B. lapidarius, 204 queens of B. pascuorum and 215 queens of $B$. pratorum. We sampled a maximum of 10 queens collected the same year and considered the mean ITD per year for each species. We preselected these four species which are easily identifiable and are represented by long time series in Belgian collections even if the sampling was more extensive at the beginning and the end of the time frame. We only considered queens collected during spring, because they are largely responsible of the success and fitness of the colony, notably during the search for suitable nesting location and the early collection of food resources (Pyke, 1978). We considered all specimens recorded in Belgium as a unique metapopulation without biogeographical structure (Maebe et al., 2016). All the specimens were conserved in entomological collections at Gembloux Agro-bio Tech, Royal Belgian Institute of Natural Sciences (IRSNB) and the University of Mons.

In order to estimate bumblebee species richness and abundance, we used the data set developed by Vray (2018). This data set used 167,729 bumblebee records from the database Banque de Données Fauniques de Gembloux et Mons (Rasmont \& Pauly, 2010) that were compiled from museum and university collections of the University of Mons, the University of Liège-Gembloux Agro Bio Tech and the Royal Belgian Institute of Natural Sciences (all the specimens were validated by Prof. P. Rasmont), scientific monitoring (e.g. Rasmont \& Pauly, 2010, http://www.atlashymenoptera. net/page.asp?xml:id=160) and citizen records from NGO initiatives (mainly the naturalist platforms https://observations.be/ and www.waarnemingen.be when the data were validated by an expert; Table S2). In order to avoid bias towards oversampled species (e.g. towards the rarest species), one record represented one observation at one date and one locality, regardless of the number of collected specimens at this date and this locality. The data from all castes have been taken into account because, whether it is a male, a worker or a queen, it indicates if the species is present or not. Even if these 167,729 opportunistic records were not collected following a standardized protocol, we are confident in the quality of our data set. Several laboratories well known in Belgium (including laboratories of coauthors) contributed to the collection of the specimens during the last decades. We know their strategy of collection of common and rare species. The relative abundance 
of the Belgian species was also confirmed by studies using standardized sampling (e.g. Vray et al., 2019).

To evaluate interspecific variation, we only considered the most abundant 22 bumblebee species (i.e. species including at least five data in each selected period described below) recorded in Belgium; it includes 15 decreasing species, two stable species and five increasing species. For each species, we attributed a mean body size value (i.e. mean body size value calculated in Gérard, Vanderplanck, et al., 2018) for the full time frame even if intraspecific variation can be observed (see results of the present study). Indeed, intraspecific variation of each species was significantly smaller than interspecific variation ( $F$ test, $p<.001)$.

\section{3 | Relative abundance of Belgian bumblebees}

We divided the initial data set in three time periods: the first time period (P1) stretches from 1910 to 1930, the second time period (P2) stretches from 1950 to 1989 and the third time period (P3) stretches from 1990 to 2016 (Table S2; 54,548 records in P1; 23,829 in P2; 89,352 in P3). P1 corresponds to a period where agricultural practices were not mechanized and before the use of chemical fertilizers. P2 corresponds to the beginning of intensive agriculture, notably with the application of the Mansholt Plan initiated in 1968 (Christians, 1998) and P3 corresponds to the establishment of agrienvironmental schemes in Europe (AES; CEC, 1998). This last period also corresponds to an intense increase of mean annual temperature and temperature deviations (IPCC, 2013). Lastly we calculated rank (from the most to the least abundant species) and the delta abundance of the 22 species in a pairwise comparative approach (Table S2).

\section{4 | Body size trends}

Prior to the analyses of body size trends at the intraspecific level (i.e. on four species), ITD measurements were rank-transformed (rntransform function, GenABEL R-package) for the only species (i.e. B. pascuorum) that did not achieve normality of the residuals. Overdispersion in variance of the data was also checked $(p>.05)$. At the intraspecific level, we assessed the correlation between (a) queen body size and time, (b) queen body size and previous year's mean annual temperature, (c) body size and patch density as well as (d) body size and edge density. We assigned mean body size of the year ' $t$ ' with mean annual temperature of the year ' $t-1$ ' to encompass the year of the larval growth. For each of these four assessed relationships, we used four distinct generalized linear models (i.e. corresponding to the four different species) with a Gaussian distribution to assess the variation of mean body size (i.e. dependent variable). Depending on the analysis, the continuous independent variable was either time, mean annual temperature, patch density or edge density (library 'stats'). As fragmentation data (i.e. patch and edge density) were calculated per decade, a mean body size per decade has been calculated at the intraspecific level.
Additionally, we performed a pairwise comparison analysis of the three time periods based on Delta Rank Abundance of the 22 bumblebee species to assess if relative population trends are correlated with their body size. We calculated linear models using the restricted maximum likelihood method and ensured that the normality of the residuals and independence requirements were satisfied (R Development Core Team, 2017). A pairwise comparison analysis with the time period as factor has also been computed at intraspecific level for the two bumblebee species including enough individuals distributed within the three time periods (i.e. B. pascuorum and B. pratorum).

\section{5 | Geographic and temporal genetic variation}

We assessed whether the genetic structure of the bumblebee species shifted over time, which could indicate a replacement by individuals from new populations with different body size. Indeed if we detect a consistent change in the population structure for each species, we cannot exclude that the body size shifts are due to individuals from new genetically different populations. If we do not detect any changes in the population structure of all species, the body size shifts are probably not due to immigrating individuals. To detect these potential temporal changes, we studied the modification of genetic structure of the four bumblebee species at the intraspecific level. We analysed both the historical and recent specimens of these four species collected at five locations in Belgium (Francorchamps, Moorsel, Nieuwpoort, Trivières, and Torgny) and genotyped with 16 microsatellite loci as described in Maebe et al. (2016). In short, historical specimens from IRSNB collected between 1913 and 1915 were genotyped with 16 microsatellite loci, and their genetic make-up compared with recent specimens collected 100 years later (2013-2015) at the exact same locations. For both time periods, 20-25 specimens were selected for each of the five selected locations. Individual chelex DNA extractions using a single middle leg, PCR amplification with 16 microsatellite loci and capillary electrophoreses were all performed as described in Maebe et al. (2013, 2015). Several validation steps were implemented following Maebe et al. (2015) including the removal of unreliable scored specimens and identified sisters by Colony 2.0 (Wang, 2004) and Kinalyzer (Ashley et al., 2009). Fstat 2.9.3 (Goudet, 2001) and GenAlEx 6.3.5 (Peakall \& Smouse, 2006) were used to detect linkage disequilibrium, and deviations from Hardy-Weinberg equilibrium. Structure v. 2.3.3 (Pritchard, Stephens, \& Donnelly, 2000) was used to invest per species population structuring. Population number $(K)$ was explored from 1 to 6 using the admixture model with 500,000 burn-in and 1,000,000 sampling steps, and this was repeated nine times for each $K$ value. The best $K$ value was determined by the Evanno method (Evanno, Regnauts, \& Goudet, 2005) embedded in Structure Harvester v.0.6.94 (Earl \& von Holdt, 2012). CLUMPP (Jakobsson \& Rosenberg, 2007) and Distruct v.1.1 (Rosenberg, 2004) were used to create a final bar plot for the best $K$ value and membership coefficient visualization, respectively.

Statistical analyses were performed using the software R version 3.3.2 (2016, https://www.r-project.org/). 


\section{3 | RESULTS}

\section{1 | Global warming and habitat fragmentation in Belgium}

Each of the models was statistically significant (Figure 1): mean annual temperature (average by year) significantly increased during the last century $\left(r^{2}=.17, d f=118, p<.001\right)$ as well as patch density $\left(r^{2}=.39, d f=11, p=.03\right)$ and edge density $\left(r^{2}=.95, d f=11, p<.001\right)$.

(a)

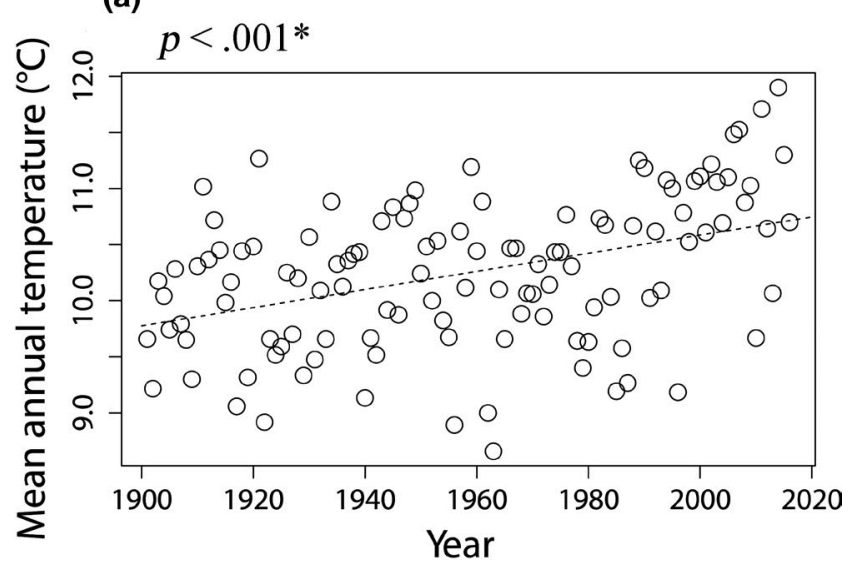

(b)

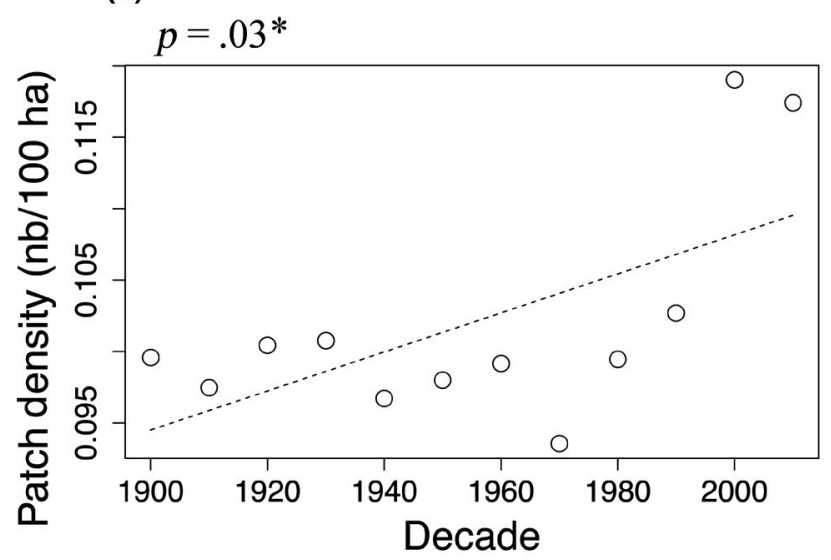

(c)

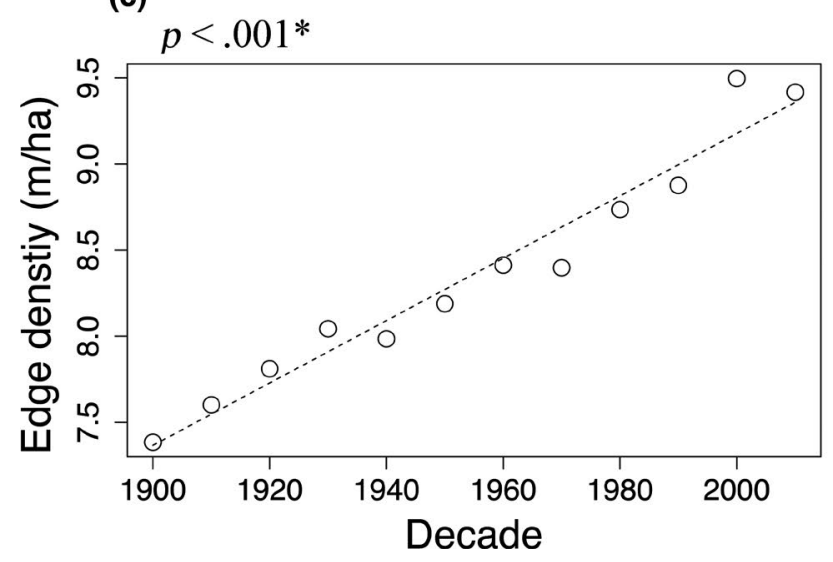

FIGURE 1 Variation over the last century in Belgium of: (a) mean annual temperature, (b) patch density and (c) edge density

\section{2 | Intraspecific variations of body size}

Based on the intraspecific data set, ITD ranged from 4.97 to $6.37 \mathrm{~mm}$ for $B$. hortorum $(N=186, S E=0.12$, mean ITD $=5.80 \mathrm{~mm}$ ), from 5.62 to $6.91 \mathrm{~mm}$ for $B$. lapidarius $(N=290, S E=0.09$, mean ITD = $6.21 \mathrm{~mm}$ ), from 4.25 to $6.02 \mathrm{~mm}$ for B. pascuorum $(N=204$, $S E=0.13$, mean ITD $=5.16 \mathrm{~mm}$ ) and from 4.32 to $6.15 \mathrm{~mm}$ for $B$. pratorum $(N=215, S E=0.1$, mean ITD $=5.38 \mathrm{~mm}$ ). The mean body size significantly increased between $\mathrm{P} 1$ and $\mathrm{P} 3$ for each species ( $t$ test, $p<.001$ ). Specifically, the mean body size of $B$. hortorum increased by $4.23 \%$ (P1 mean ITD $=5.67$, P3 mean ITD $=5.91$ ), that of $B$. lapidarius by $3.12 \%$ (P1 mean ITD $=6.09$, P3 mean ITD $=6.28$ ), that of $B$. pascuorum by $6.6 \%(P 1$ mean ITD $=5.03$, P3 mean ITD $=5.36)$ and that of $B$. pratorum by $2.9 \%$ ( 11 mean ITD $=5.29$, P3 mean ITD $=5.44$ ). Based on linear models, mean body size of B.hortorum increased significantly during the last century $\left(r^{2}=.45, d f=39, p<.001\right.$, Figure 2$)$, as did the mean body size of $B$. lapidarius $\left(r^{2}=.26, d f=44, p<.001\right.$, Figure 2$)$, the mean body size of $B$. pratorum $\left(r^{2}=.20, d f=58, p<.001\right)$ and the mean body size of $B$. pascuorum $\left(r^{2}=.35, d f=61, p<.001\right)$.

When we focused on the comparison of the three selected time periods (i.e. for the two bumblebee species including enough individuals distributed within the three time periods), the ITD of $B$. pratorum has significantly increased during the last century (Kruskal-Wallis $\chi^{2}=19.083, d f=2, p<.001$ ) as well as the ITD of $B$. pascuorum (Kruskal-Wallis $\chi^{2}=61.735, d f=2, p<.001$ ). Post hoc Mann-Whitney $U$ test showed that this increase was significant between each temporal period predefined for B. pascuorum $(p<.05)$. For B. pratorum, body size significantly increased between P1 and P2 $(p<.001)$, but was not significantly different between P2 and P3 $(p>$.05).

Increase in mean body size was correlated to the increase in mean annual temperature for each of the tested species: $B$. hortorum $\left(r^{2}=.14, d f=39, p=.018\right)$, B. lapidarius $\left(r^{2}=.14, d f=44, p=.011\right)$, B. pascuorum $\left(r^{2}=.14, d f=61, p=.003\right)$ and B. pratorum $\left(r^{2}=.12\right.$, $d f=58, p=.012$ ). Mean body size of each species also significantly increased with the two metrics of habitat fragmentation. The mean body size significantly increased with increasing patch density for $B$. hortorum $\left(r^{2}=.58, d f=7, p=.03\right)$, B. lapidarius $\left(r^{2}=.51, d f=8, p=.03\right)$, B. pascuorum $\left(r^{2}=.44, d f=10, p=.03\right)$ and B. pratorum $\left(r^{2}=.50\right.$, $d f=10, p=.01)$. Mean body size also significantly increased with increasing edge density for $B$. hortorum $\left(r^{2}=.68, d f=7, p=.01\right), B$. lapidarius $\left(r^{2}=.78, d f=8, p=.002\right)$, B. pascuorum $\left(r^{2}=.80, d f=10\right.$, $p<.001)$ and B. pratorum $\left(r^{2}=.45, d f=10, p=.02\right)$.

\section{3 | Interspecific variation of body size}

Mean ITD of the 22 Belgian species ranged from 4.69 to $6.61 \mathrm{~mm}$. Mean ITD was significantly correlated to delta rank abundance between P1-P2 $\left(r^{2}=.19, d f=20, p=.04\right.$, Figure 3) and P1-P3 $\left(r^{2}=.22\right.$, $d f=20, p=.02$, Figure 3). However, no significant correlation was found when comparing bumblebee body size and delta rank abundance between P2 and P3 ( $r^{2}=.01, d f=20, p>.05$, Figure 3$)$. 

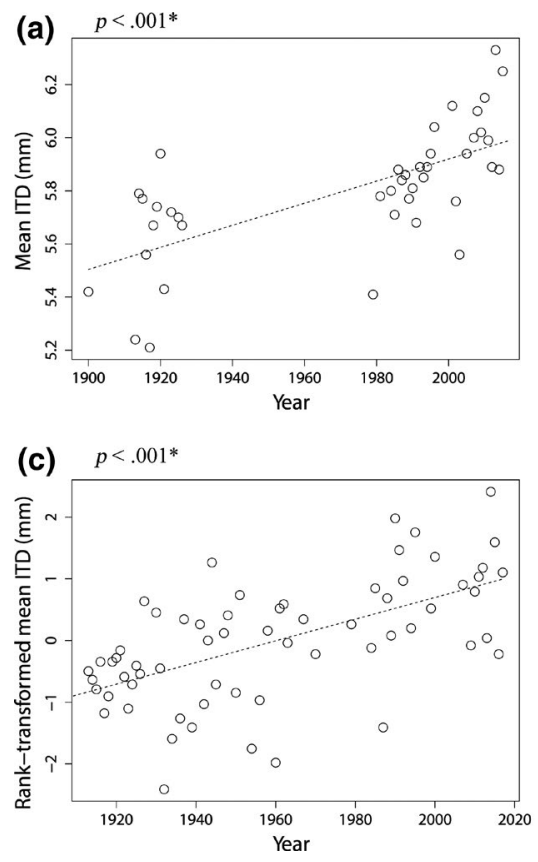

(a) $p=.04 *$

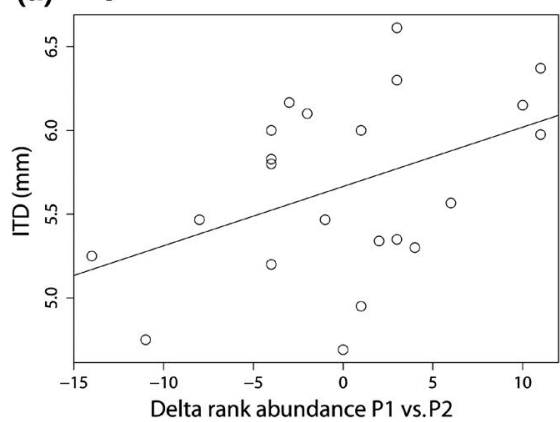

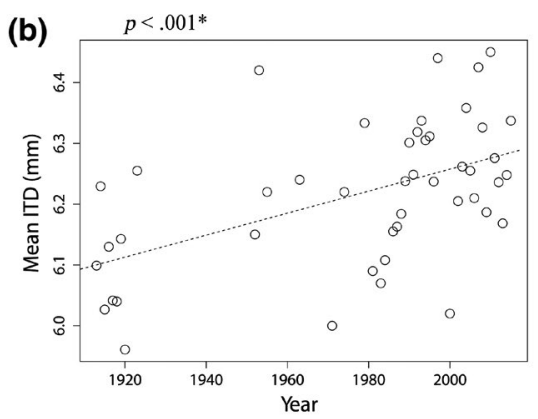

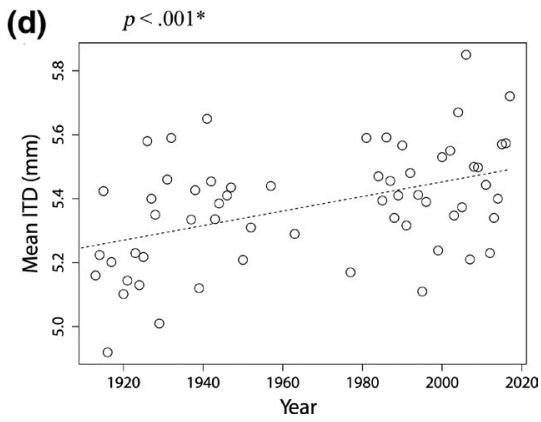

(b) $\quad p=.02^{*}$

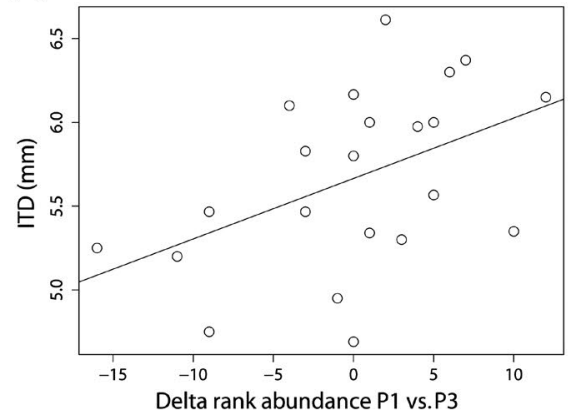

FIGURE 2 Intraspecific variation of queen bumblebee body size over the last century in Belgium. (a) Bombus hortorum ( $n=41, p<.001, r=.67$ ). (b) Bombus lapidarius ( $n=46, p<.001, r=.51$ ). (c) Bombus pascuorum ( $n=63, p<.001$, $r=.6$ ). (d) Bombus pratorum ( $n=60$, $p<.001, r=.45$ )

FIGURE 3 Queen bumblebee body size of the 22 most frequently recorded species in Belgium in relation to their specific delta-rank abundance along three time periods. (a) Period 1 (1910-1930) versus Period 2 (1950-1989; $n=22, p=.04, r=.44)$. (b) Period 1 (1910-1930) versus Period 3 (1990-2016; $n=22, p=.02, r=.47)$. (c) Period 2 (1950-1989) versus Period $3(1990-2016 ; n=22, p>.05, r=.1)$

\section{4 | Geographic and temporal genetic variation}

From the 820 genotyped specimens, 51 specimens could not be scored reliably. Moreover 120 specimens were identified as sisters and discarded. All further analyses were therefore performed with the 649 remaining specimens. For three species (B. lapidarius, B. pascuorum and $B$. pratorum) the best fitting $K$ value was 2 (Figure $S 1$ ). The only exception was $B$. hortorum for which we identified $K=3$ (Figure S1). Although population structuring was detected in each species (spatially and/or temporally), this was not systematically due to temporal changes. Indeed, our structure results showed that temporal clustering was only present in two out of the four species: B. lapidarius and B. pratorum. In these two species, all specimens from recent populations were grouped together in one cluster, while almost all historical specimens formed the other cluster (Figure 4). Conversely no temporal population structuring was present between historical and recent Belgian populations in $B$. hortorum and B. pascuorum (Figure 4).

\section{4 | DISCUSSION}

Here we show that average queen body size increased during the last century in Belgium. This trend has been observed intraspecifically in the four tested species (i.e. B. hortorum, B. lapidarius, B. pascuorum and B. pratorum) and also interspecifically, as species showing the greatest declines had the smallest body sizes and largest species increased in abundance, resulting in an increase in average bumblebee body size at the community level. Even though body size clines in bees can be driven by temperature and innate thermoregulatory abilities (Bishop \& Armbruster, 1999), these factors do not seem to be the main drivers of bumblebee body size along temporal series. Indeed, if global warming had shaped the body size trends of bumblebee queens (i.e. in accordance with the predictions of the temporal extension of Bergmann's rule), we would have expected a decrease in body size, particularly between P2 (i.e. 1950-1989) and P3 (i.e. 1990-2016). As the inverse trend is observed (and with low coefficient of determination), some mechanisms seem to counteract 
B. hortorum ( $\mathrm{K}=3$ )

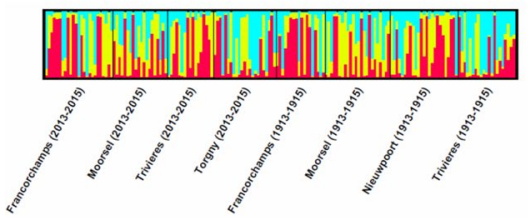

B. pascuorum (K=2)

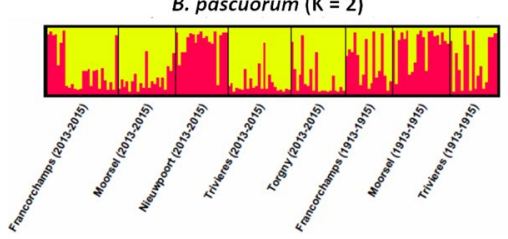

B. Iapidarius $(\mathrm{K}=2)$
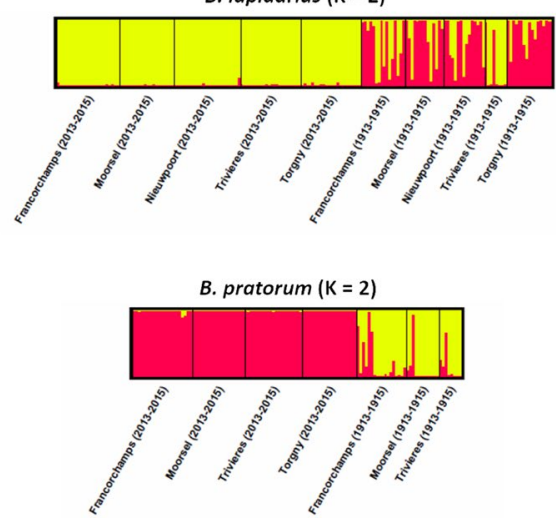

FIGURE 4 Species-specific Bayesian clustering of four bumblebee species in five Belgian localities over the last century. Each bar represents a single bumblebee specimen, which is assigned by colour to a cluster. In case of $K=2$; two clusters and colours are present, in case of $K=3$, there are three clusters and colours. Black vertical lines define the original populations to which these specimens belonged the effect of global warming on body size. However, we cannot exclude the hypothesis that global warming could increase the season length and thus allows bumblebees to develop a larger adult size (Horne, Hirst, \& Atkinson, 2015).

The observed pattern could thus be caused by the habitat modification and agricultural intensification that has occurred in Belgium. Indeed, fragmentation of bumblebee habitat strongly increased in this country during the last century (Figure 1b,c; EEA Report, 2011). It could have shaped bumblebee body size modification, since in a fragmented environment larger individuals are probably better able to colonize new patches of suitable habitats (e.g. with suitable nesting sites) and have a higher tolerance to starvation (Cushman, Lawton, \& Manly, 1993; Peters, 1983). Moreover it is known that average bee foraging ranges are related to body size (Greenleaf et al., 2007). Bigger bumblebee queens could forage more easily on isolated distant patches while smaller bees could be more sensitive to land-use fragmentation (Steffan-Dewenter, Munzenberg, Bürger, Thies, \& Tscharntke, 2002). It could be a major mechanism of body-size shift as it was first suggested at a local scale in a study on Andrena species (Warzecha et al., 2016). Even in metapopulation dynamics, larger and more mobile species are able to persist under harsh conditions if the immigration rate is high enough (Hanski, 1994). Habitat fragmentation is thus increasingly identified as a major driver of body size composition and ecosystem structure (Grass, Jauker, Steffan-Dewenter, Tscharntke, \& Jauker, 2018), at least for taxa where body size is linked to dispersal capacity (Merckx, Kaiser, et al., 2018; Merckx, Souffreau, et al., 2018). Additionally, body size shifts were mainly observed between the first period (1910-1930) and the second period (19501989) of the time frame investigated in this study, which corroborates the hypothesis of the impact of habitat fragmentation and agricultural intensification on bumblebee body size. Indeed, a significant part of favourable habitats for bees has been lost and/or fragmented between P1 and P2, notably in consequence of the Mansholt Plan and the increasing number of large monocultural crops (Christians, 1998). The selection towards larger individuals due to their increased flight ability could also be strengthened because larger body size also improves access to resources by a better competitive capacity (Inoue \& Yokoyama, 2006). Similarly, as pesticide use has strongly increased since the middle of the 20th century, a selective pressure favouring larger individuals could also have acted consequently to pesticide resistance. Indeed, bigger bumblebees have a higher LD50 (i.e. median lethal dose) than smaller bumblebees, facilitating greater resistance to the intensification of pesticide use (Mommaerts \& Smagghe, 2011; Thompson, 2001; Van der Steen, 1994). By contrast, diet modification is probably not a driver of body size variation in the framework of this study. If the decrease in diet quality or quantity impacted body size, the converse body size trend (i.e. decrease in body size) would had been observed as lower diet quality are known to decrease body size (Roulston \& Cane, 2002). Moreover, the diet quality of common bumblebees in Belgium has been stable for the past few decades (Roger et al., 2017) and invasive plant species are not known to systematically impact bumblebee resource intake negatively (Drossart, Michez, \& Vanderplanck, 2017) which probably excludes diet as a major factor of the body size modification in queen bumblebees during the last century. Finally, based on genetic structure analysis, we found no evidence that size increase could be systematically explained by replacement of new populations of larger bumblebees. However, the increase in body size in the Belgian bumblebee populations can still have a genetic basis due to natural selection on loci expressing body size differences and local adaptation.

As a benchmark to these results, there are few studies based on long time series of body size variation within insects. To our knowledge, body size of many insect species decreased during the last decades (Ohlberger, 2013), for example in arctic butterflies (Bowden et al., 2015). When focusing on bumblebees, the results are contrasting. Indeed, Bergmann's rule was found to apply in several bumblebee species across a restricted geographical area and during the same time period (e.g. Great-Britain; Peat et al., 2005; Scriven et al., 2016). In these conditions, body size clines seem to corroborate the 'thermoregulatory hypothesis'. However, the converse Bergmann's rule is observed at larger geographical scales (Gérard, Vanderplanck, et al., 2018; Ramirez-Delgado et al., 2016) and during longer time periods such as that in the present study. At larger/longer temporal and/or geographical scales, it seems that alternative mechanisms like habitat fragmentation and modification can counteract the effect on temperature of body size (Merckx, Kaiser, et al., 2018; Merckx, Souffreau, et al., 2018). Due to their heterothermic behaviour, increasing body size can lead to better thermoregulatory efficiency 
(Bischop \& Armbruster, 1999). Thus larger bumblebees would be more efficient in cooling the colony. Consequently, habitat fragmentation is the most likely explanation of the observed trends but possibly helped by a drive for better cooling abilities by larger individuals due to climatic change.

Shifts in body size have obvious ecological implications in the animal kingdom. For example, it is expected that global warming will negatively impact animal fitness through a reduction in average size (Kingsolver \& Huey, 2008; Merckx, Kaiser, et al., 2018; Merckx, Souffreau, et al., 2018). Incidentally, Kingsolver and Huey (2008) proposed the rule 'Bigger is better' which often applies in animals, as many aspects of organism performance are enhanced by a larger body size (Bonner, 2006). A decrease of both bumblebee and wild bee body size could have strong implications for pollination. Indeed, pollination efficiency decreases with smaller bumblebees (Jauker, Speckmann, \& Wolters, 2016; Willmer \& Finlayson, 2014). However, pollination service is mostly linked to the worker caste in bumblebees. Even if a selective pressure could occur towards larger queens, the trends could be different in workers. At the end of the hibernation, larger body size is particularly crucial because smaller queens would lack energy to search for a nest and initiate the colony if the habitat is too fragmented. Due to the high variability of worker body size in bumblebees, workers could be more resilient to a selective pressure towards larger individuals. Moreover, it is known that heritability of body size is quite low in bees and that body size of a generation is mainly determined by the nutritional status of the previous generation, thus we cannot be certain of the same trend in the other castes (e.g. Couvillon \& Dornhaus, 2009; Owen \& McCorquodale, 1994; Tepedino, Thompson, \& Torchio, 1984). Our results thus highlight the novelty to evaluate the impact of alternative global change factors on body size modification in animals.

\section{ACKNOWLEDGEMENTS}

We are very grateful for collection access to the curators of the following museums: Wouter Dekoninck and Yvonnick Gérard, IRSNB (Bruxelles, Belgium), Frédéric Francis, GxABT (Gembloux, Belgium). This work was partly supported by the 'Fonds de la Recherche Scientifique - FNRS', the Research Foundation-Flanders (FWO) under EOS Project named CLIPS ( ${ }^{\circ}$ 3094785), and the Belgian Science Policy (project BR/132/A1/BELBEES). MG was supported by a grant from the Belgian Fonds pour la Recherche dans I'Industrie et l'Agriculture (FRIA). This work was supported by the Research FoundationFlanders (FWO research project 3G042618). BM is a PhD student who received grants from the FRS-FNRS (Fonds de la Recherche Scientifique). We also thank Dr. Thomas J. Wood for the proofreading as a native speaker, Dr. Maryse Vanderplanck for assistance on statistical analyses and Dr. Richard Fuchs for kindly providing us the HILDA maps of Belgium. Finally, we thank P. Decuypere, M. Drossart and J. Raes for providing the pictures for the graphical abstract.

\section{CONFLICT OF INTEREST}

The authors declare that they have no competing interests.

\section{ORCID}

Maxence Gérard iD https://orcid.org/0000-0002-2485-0662

\section{REFERENCES}

Ashley,M.V.,Caballero,I.C.,Chaovalitwongse,W., Dasgupta, B., Govindan, P., Sheikh, S. I., \& Berger-wolf, T. Y. (2009). Kinalyzer, a computer program for reconstructing sibling groups. Molecular Ecology Resources, 9, 1127-1131. https://doi.org/10.1111/j.1755-0998.2009.02562.x

Azevedo, R. B. R., French, V., \& Partridge, L. (2002). Temperature modulates epidermal cell size in Drosophila melanogaster. Journal of Insect Physiology, 48, 231-237. https://doi.org/10.1016/S0022-1910 00168-8

Beasley, D. E., Penick, C. A., Boateng, N. S., Menninger, H. L., \& Dunn, R. R. (2018). Urbanization disrupts latitude-size rule in 17-year cicadas. Ecology and Evolution, 8, 2534-2541. https://doi.org/10.1002/ ece3.3879

Bishop, J. A., \& Armbruster, W. S. (1999). Thermoregulatory abilities of Alaskanbees:Effects of size, phylogenyandecology. FunctionalEcology, 13, 711-724. https://doi.org/10.1046/j.1365-2435.1999.00351.x

Bonner, J. T. (2006). Why size matters. Princeton, NJ: Princeton University Press.

Bowden, J. J., Eskildsen, A., Hansen, R. R., Olsen, K., Kurle, C. M., \& Hoye, T. T. (2015). High-Arctic butterflies become smaller with rising temperatures. Biology Letters, 11, 20150574. https://doi.org/10.1098/ rsbl.2015.0574

Brans, K. I., Govaert, L., Engelen, J. M., Gianuca, A. T., Souffreau, C., \& De Meester, L. (2017). Eco-evolutionary dynamics in urbanized landscapes: Evolution, species sorting and the change in zooplankton body size along urbanization gradients. Philosophical Transactions of the Royal Society B: Biological Sciences, 372, 20160030. https://doi. org/10.1098/rstb.2016.0030

Brans, K. I., Jansen, M., Vanoverbeke, J., Tüzün, N., Stoks, R., \& De Meester, L. (2017). The heat is on: Genetic adaptation to urbanization mediated by thermal tolerance and body size. Global Change Biology, 23, 5218-5227. https://doi.org/10.1111/gcb.13784

Cane, J. H. (1987). Estimation of bee size using intertegular span (Apoidea). Journal of the Kansas Entomological Society, 60, 145-147.

CEC. (1998). Evaluation of agri-environment programmes, State of Application of Regulation (EEC) No. 2078/92. DGVI Working Document, VI/76555/98.

Christians, C. (1998). Quarante ans de politique Agricole européenne commune et d'agriculture en Belgique. Bulletin De La Société Géographique De Liège, 35, 41-55.

Classen, A., Steffan-Dewenter, I., Kindeketa, W. J., \& Peters, M. K. (2017). Integrating intraspecific variation in community ecology unifies theories on body size shifts along climatic gradients. Functional Ecology, 31, 768-777. https://doi.org/10.1111/1365-2435.12786

Core Team, R. (2017). R: A language and environment for statistical computing. Vienna, Austria: R Foundation for Statistical Computing.

Couvillon, M. J., \& Dornhaus, A. (2009) Location, location, location: Larvae position inside the nest is correlated with adult body size in worker bumble-bees (Bombus impatiens). Proceedings of the Royal Society of London Series B, Biological Sciences, 276, 2411-2418. https:// doi.org/10.1098/rspb.2009.0172

Cushman, J. H., Lawton, J. H., \& Manly, B. F. J. (1993). Latitudinal patterns in European ant assemblages: Variation in species richness and body size. Oecologia, 95, 30-37. https://doi.org/10.1007/BF00649503

Dellicour, S., Gérard, M., Prunier, J. G., Dewulf, A., Kuhlmann, M., \& Michez, D. (2017). Distribution and predictors of wing shape and size variability in three sister species of solitary bees. PLoS ONE, 3 , e0173109. https://doi.org/10.1371/journal.pone.0173109

Dirzo, R., Young, H. S., Galetti, M., Ceballos, G., Isaac, N. J. B., Collen, B. (2014). Defaunation in the Anthropocene. Science, 345, 401-406. https://doi.org/10.1126/science.1179504 
Drossart, M., Michez, D., \& Vanderplanck, M. (2017). Invasive plants as potential food resource for native pollinators: A case study with two invasive species and a generalist bumble bee. Scientific Reports, 7, 16242. https://doi.org/10.1038/s41598-017-16054-5

Earl, D. A., \& von Holdt, B. M. (2012). Structure harvester: A website and program for visualizing structure output and implementing the Evanno method. Conservation Genetic Resources, 4, 359-361. https:// doi.org/10.1007/s12686-011-9548-7

European Environment Agency.(2011). Landscape fragmentation in Europe, 88pp.

Evanno, G., Regnauts, S., \& Goudet, J. (2005). Detecting the number of clusters of individuals using the software structure: A simulation study. Molecular Ecology, 14, 2611-2620. https://doi.org/10. 1111/j.1365-294X.2005.02553.x

Ford, K. R., Harrington, C. A., Bansal, S., Gould, P. J., \& Clair, B. S. (2016). Will changes in phenology track climate change? A study of growth initiation timing in coast Douglas-fir. Global Change Biology, 22, 37123723. https://doi.org/10.1111/gcb.13328

Fuchs, R., Herold, M., Verburg, P. H., \& Clevers, J. G. P. W. (2013). A high-resolution and harmonized model approach for reconstructing an analysing historic land changes in Europe. Biogeosciences, 10, 1543-1559. https://doi.org/10.5194/bg-10-1543-2013

Fuchs, R., Herold, M., Verburg, P. H., Clevers, J. G. P. W., \& Eberle, J. (2015). Gross changes in reconstructions of historic land cover/use for Europe between 1900 and 2010. Global Change Biology, 21, 299313. https://doi.org/10.1111/gcb.12714

Fusco, G., \& Minelli, A. (2010). Phenotypic plasticity in development and evolution: Facts and concepts. Philosophical Transactions of the Royal Society B., 365, 547-556. https://doi.org/10.1098/rstb.2009. 0267

Gardner, J. L., Peters, A., Kearney, M. R., Joseph, L., \& Heinsohn, R. (2011). Declining body size: A third universal response to warming? Trends in Ecology \& Evolution, 26, 285-291. https://doi.org/10.1016/ j.tree.2011.03.005

Gérard, M., Michez, D., Debat, V., Fullgrabe, L., Meeus, I., Piot, N., ... Vanderplanck, M. (2018). Stressful conditions reveal decrease in size, modification of shape but relatively stable asymmetry in bumblebee wings. Scientific Reports, 8, 15169. https://doi.org/10.1038/ s41598-018-33429-4

Gérard, M., Vanderplanck, M., Franzen, M., Kuhlmann, M., Potts, G. S., Rasmont, P., ... Michez, D. (2018). Patterns of size variation in bees at a continental scale: Does Bergmann's rule apply? Oikos, 127, 10951103. https://doi.org/10.1111/oik.05260

Gienapp, P., Teplitsky, C., Alho, J. S., Mills, J. A., \& Merila, J. (2008). Climate change and evolution: Disentangling environmental and genetic responses. Molecular Ecology, 17, 167-178. https://doi. org/10.1111/j.1365-294X.2007.03413.x

Goudet, J. (2001). Fstat: A program to estimate and test gene diversities and fixation indices (version 2.9.3). Updated from Goudet, J (1995): Fstat (version 1.2): A computer program to calculate F - Statistics. Journal of Heredity, 86, 485-486. https://doi.org/10.1093/oxfordjour nals.jhered.a111627

Goulson, D., Nicholls, E., Botías, C., \& Rotheray, E. L. (2015). Bee declines driven by combined stress from parasites, pesticides, and lack of flowers. Science, 347, 1255957. https://doi.org/10.1126/science. 1255957

Grass, I., Jauker, B., Steffan-Dewenter, I., Tscharntke, T., \& Jauker, F. (2018). Past and potential future effects of habitat fragmentation on structure and stability of plant-pollinator and host-parasitoid networks. Nature Ecology \& Evolution, 2, 1408-1417. https://doi. org/10.1038/s41559-018-0631-2

Greenleaf, S. S., Williams, N. M., Winfree, R., \& Kremen, C. (2007). Bee foraging ranges and their relationship to body size. Oecologia, 153, 589-596. https://doi.org/10.1007/s00442-007-0752-9
Grether, G. F. (2005). Environmental change, phenotypic plasticity and genetic compensation. The American Naturalist, 166, 115-123. https:// doi.org/10.1086/432023

Hanski, I. (1994). A practical model of metapopulation dynamics. Journal of Animal Ecology, 63, 151-162. https://doi.org/10.2307/5591

Hawkins, B. A. (1995). Latitudinal body-size gradients for the bees of the eastern United States. Ecological Entomology, 20, 195-198. https:// doi.org/10.1111/j.1365-2311.1995.tb00446.x

Hesselbarth, M. H. K., Sciaini, M., Nowosad, J., \& Hanss, S. (2019). Landscapemetrics: Landscape metrics for categorical map patterns. R package version 1.1. Retrieved from https://CRAN.R-project.org/ package=landscapemetrics

Hickling, R., Roy, D. B., Hill, J. K., Fox, R., \& Thomas, C. D. (2006). The distributions of a wide range of taxonomic groups are expanding polewards. Global Change Biology, 12, 450-455. https://doi. org/10.1111/j.1365-2486.2006.01116.x

Horne, C. R., Hirst, A. G., \& Atkinson, D. (2015). Temperature-size responses match latitudinal-size clines in arthropods, revealing critical differences between aquatic and terrestrial species. Ecology Letters, 18, 327-335. https://doi.org/10.1111/ele.12413

Huey, R. B., Gilchrist, G. W., Carlson, M. L., Berrigan, D., \& Serra, L. (2000). Rapid evolution of a geographic cline in size in an introduced fly. Science, 287, 308-309. https://doi.org/10.1101/550319

Inoue, M. I., \& Yokoyama, J. (2006). Morphological variation in relation to flower use in bumblebees. Entomological Science, 9, 147-159. https:// doi.org/10.1111/j.1479-8298.2006.00162.x

IPCC. (2013). Climate change 2013: The physical science basis. Contribution of Working Group I to 5th Assessment Report of the Intergovernmental Panel on Climate Change. Cambridge, UK: Cambridge University Press. 1535 pp.

Jakobsson, M., \& Rosenberg, N. A. (2007). CLUMPP: A cluster matching and permutation program for dealing with label switching and multimodality in analysis of population structure. Bioinformatics, 23, 1801-1806. https://doi.org/10.1093/bioinformatics/btm233

Jauker, F., Speckmann, M., \& Wolters, V. (2016). Intra-specific body size determines pollination effectiveness. Basic and Applied Ecology, 17, 714-719. https://doi.org/10.1016/j.baae.2016.07.004

Kerr, J. T., Pindar, A., Galpern, P., Packer, L., Potts, S. G., Roberts, S. M., ... Pantoja, A. (2015). Climate change impacts on bumblebees converge across continents. Science, 349, 177-180. https://doi.org/10.1126/ science.aaa7031

Kingsolver, J. G., \& Huey, R. B. (2008). Size, temperature and fitness: Three rules. Evolutionary Ecology Research, 10, 251-268.

Klein, A. M., Vaissière, B. E., Cane, J. H., Steffan-Dewenter, I., Cunningham, S. A., Kremen, C., \& Tscharntke, T. (2007). Importance of pollinators in changing landscapes for world crops. Proceedings of the Royal Society B: Biological Sciences, 274(1608), 303-313. https:// doi.org/10.1098/rspb.2006.3721

Maebe, K., Meeus, I., Ganne, M., De Meulemeester, T., Biesmeijer, K., \& Smagghe, G. (2015). Microsatellite analysis of museum specimens reveals historical differences in genetic diversity between declining and more stable Bombus species. PLoS ONE, 10, e0127870. https:// doi.org/10.1371/journal.pone.0127870

Maebe, K., Meeus, I., Maharramov, J., Grootaert, P., Michez, D., Rasmont, P., \& Smagghe, G. (2013). Microsatellite analysis in museum samples reveals inbreeding before the regression of Bombus veteranus. Apidologie, 44(2), 188-197. https://doi.org/10.1007/s13592012-0170-9

Maebe, K., Meeus, I., Vray, S., Claeys, T., Dekoninck, W., Boevé, J.-L., ... Smagghe, G. (2016). A century of temporal stability of genetic diversity in wild bumblebees. Scientific Reports, 6, https://doi.org/ 10.1038/srep3829

McCabe, J., French, V., \& Partridge, L. (1997). Joint regulation of cell size and cell number in the wing blade of Drosophila melanogaster. 
Genetics Research, 69, 61-68. https://doi.org/10.1017/S001667239 7002620

McCarty, J. P. (2001). Ecological consequences of recent climate change. Conservation Biology, 15, 320-331. https://doi.org/10.1046/j.15231739.2001.015002320.x

McGarigal, K., Cushman, S. A., \& Ene, E. (2012). FRAGSTATS v4: Spatial pattern analysis program for categorical and continuous maps. Computer software program produced by the authors at the University of Massachusetts, Amherst. Retrieved from http://www. umass.edu/landeco/research/fragstats/fragstats.html

McNab, N. B. (2010). Geographic and temporal correlations of mammalian size reconsidered: A resource rule. Oecologia, 164, 13-23. https:// doi.org/10.1007/s00442-010-1621-5

Merckx, T., Kaiser, A., \& Van Dyck, H. (2018). Increased body size along urbanization gradients at both community and intraspecific level in macro-moths. Global Change Biology, 24, 3837-3848. https://doi. org/10.1111/gcb.14151

Merckx, T., Souffreau, C., Kaiser, A., Baardsen, L. F., Backeljau, T., Bonte, D., ... Van Dyck, H. (2018). Body-size shifts in aquatic and terrestrial urban communities. Nature, 558, 113. https://doi.org/10.1038/ s41586-018-0140-0

Millien, V., Lyons, S. K., Olson, L., Smith, S. A., Wilson, A. B., \& YomTov, Y. (2006). Ecotypic variation in the context of global climate change revisiting the rules. Ecology Letters, 9, 853-869. https://doi. org/10.1111/j.1461-0248.2006.00928.x

Mommaerts, V., \& Smagghe, G. (2011). Side-effects of pesticides on the pollinator Bombus: An overview. In M. Stoytcheva (Ed.), Pesticides in the modern world - Pests control and pesticides exposure and toxicity assessment (pp. 507-552). Croatia: In Tech Publishing. ISBN 978-953-307-457-3.

Müller, A., Diener, S., Schnyder, S., Stutz, K., Sedivy, C., \& Dorn, S. (2006). Quantitative pollen requirements of solitary bees: Implications for bee conservation and the evolution of bee-flower relationships. Biological Conservation, 130, 604-615. https://doi.org/10.1016/j. biocon.2006.01.023

Nijhout, H. F. (2003). The control of body size in insects. Developmental Biology, 231, 1-9. https://doi.org/10.1016/S0012-1606(03)00276-8

Ohlberger, J. (2013). Climate warming and ectotherm body size-From individual physiology to community ecology. Functional Ecology, 27, 991-1001. https://doi.org/10.1111/1365-2435.12098

Ollerton, J. (2018). Pollinator diversity: Distribution, ecological function, and conservation. Annual Review of Ecology, Evolution, and Systematics, 48, 353-376. https://doi.org/10.1146/annurev-ecols ys-110316-022919

Owen,R.E.,\&McCorquodale,D.B.(1994).Quantitativevariationandheritability of postdiapause development time and body size in the alfalfa leaf cutting bee (Hymenoptera: Megachilidae). Annals of the Entomological Society of America, 87, 922-927. https://doi.org/10.1093/aesa/87. 6.922

Peakall, R., \& Smouse, F. (2006). GENALEX 6: Genetic analysis in excel. Population genetic software for teaching and research. Molecular Ecology Notes, 6, 288-295. https://doi.org/10.1111/j.1471-8286. 2005.01155.x

Peat, J., Darvill, B., Ellis, J., \& Goulson, D. (2005). Effects of climate on intra- and interspecific size variation in bumble-bees. Functional Ecology, 19, 145-151. https://doi.org/10.1111/j.02698463.2005.00946.x

Peters, M. K., Peisker, J., Steffan-Dewenter, I., \& Hoiss, B. (2016). Morphological traits are linked to the cold performance and distribution of bees along elevational gradients. Journal of Biogeography, 43(10), 2040-2049. https://doi.org/10.1111/jbi.12768

Peters, R. H. (1983). The ecological implications of body size. Cambridge, UK: Cambridge University Press.

Pritchard, J. K., Stephens, M., \& Donnelly, P. (2000). Inference of population structure using multilocus genotype data. Genetics, 155, 945-959.
Pyke, G. H. (1978). Optimal body size in bumblebees. Oecologia, 34, 255266. https://doi.org/10.1007/BF00344905

Ramirez-Delgado, V. H., Sanabria-Urban, S., Serrano-Meneses, M. A., \& Cueva Del Castillo, R. (2016). The converse to Bergmann's rule in bumblebees, a phylogenetic approach. Ecology and Evolution, 6, 6160-6169. https://doi.org/10.1002/ece3.2321

Rasmont, P., Franzen, M., Lecocq, T., Harpke, A., Roberts, S., Biesmeijer, K., ... Schweiger, O. (2015). Climatic risk and distribution atlas of European bumblebees. Biodiversity and Ecosystem Risk Assessment, 10, 1-236. https://doi.org/10.3897/biorisk.10.4749

Rasmont, P., Genoud, D., Gadoum, S., Aubert, M., Dufrène, E., Le Goff, G., ... Pauly, A. (2017). Hymenoptera Apoidae Gallica: Liste des abeilles sauvages de Belgique, France, Luxembourg et Suisse. Editions Atlas Hymenoptera. Mons, Belgium: Université de Mons.

Rasmont, P., \& Pauly, A. (2010).Les bourdons de la Belgique. In: Atlas Hymenoptera, Mons, Gembloux. Retrieved from http://www.atlas hymenoptera.net/page.asp?xml:id=160

Roger, N., Moerman, R., Carvalheiro, L. G., Aguirre-Guitiérrez, J., Jacquemart, A.-L., Kleijn, D., ... Michez, D. (2017). Impact of pollen resources drift on common bumblebees in NW Europe. Global Change Biology, 23, 68-76. https://doi.org/10.1111/gcb.13373

Romano, A., \& Ficetola, G. F. (2010). Ecogeographic variation of body size in the spectacled salamanders (Salamandrina): Influence of genetic structure and local factors. Journal of Biogeography, 37, 2358-2370. https://doi.org/10.1111/j.1365-2699.2010.02369.x

Rosenberg, N. A. (2004). Distruct: A program for the graphical display of population structure. Molecular Ecology Notes, 4, 137-138. https:// doi.org/10.1046/j.1471-8286.2003.00566.x

Roulston, T. H., \& Cane, J. H. (2002). The effect of pollen protein concentration on body size in the sweat bee Lasioglossum zephyrum (Hymenoptera: Apiformes). Evolutionary Ecology, 16, 49-65. https:// doi.org/10.1023/A:1016048526475

Scheper, J., Reemer, M., van Kats, R., Ozinga, W. A., van der Linden, G. T. J., Schaminée, J. H. J., ... Kleijn, D. (2014). Museum specimens reveal loss of pollen host plants as key factor driving wild bee decline in The Netherlands. Proceedings of the National Academy of Sciences of the United States of America, 111, 17552-17557. https://doi.org/10.1073/ pnas.1412973111

Schleuning, M., Fründ, J., Schweiger, O., Welk, E., Albrecht, J., Albrecht, M., ... Hof, C. (2016). Ecological networks are more sensitive to plant than to animal extinction under climate change. Nature Communication, 7, 13965. https://doi.org/10.1038/ncomm s13965

Scriven, J. J., Whitehorm, P. R., Goulson, D., \& Tinsley, M. C. (2016). Bergmann's body size rule operates in facultatively endothermic insects: Evidence from a complex of cryptic bumblebee species. PLoS ONE, 11(10), https://doi.org/10.1371/journ al.pone. 0163307

Steffan-Dewenter, I., Munzenberg, U., Bürger, C., Thies, C., \& Tscharntke, T. (2002). Scale-dependent effects of landscape context on three pollinator guilds. Ecology, 83, 1421-1432. https://doi. org/10.2307/3071954

Strahan, R. T., Sanchez Meador, A. J., Huffman, D. W., \& Laughlin, D. C. (2016). Shifts in community-level traits and functional diversity in a mixed conifer forest: A legacy of land-use change. Journal of Applied Ecology, 53, 1755-1765. https://doi.org/10.1111/13652664.12737

Tepedino, V. J., Thompson, R., \& Torchio, P. F. (1984). Heritability for size in the Megachilid Bee Osmia lignaria propinqua Cresson. Apidologie, 15, 83-88. https://doi.org/10.1051/apido:19840108

The World Conservation Union. (2014). IUCN Red List of Threatened Species (2014).3.Summary Statistics for Globally Threatened Species.

Thompson, H. M. (2001). Assessing the exposure and toxicity of pesticides to bumblebees (Bombus sp.). Apidologie, 32, 305-321. https:// doi.org/10.1051/apido:2001131 
Umina, P. A., Weeks, A. R., Kearney, M. R., McKechnie, S. W., \& Hoffmann, A. A. (2005). A rapid shift in a classic clinal pattern in Drosophila reflecting climate change. Science, 308, 691-693. https:// doi.org/10.1126/science.1109523

Van der Steen, J. J. M. (1994). Method development for the determination of the contact LD50 of pesticides to bumblebees (Bombus terrestris L.). Apidologie, 25, 463-465.

Virgós, E., Kowalczyk, R., Trua, A., de Marinis, A., Mangas, J. G., Barea-Azcón, J. M., \& Geffen, E. (2011). Body size clines in the European badger and the abundant centre hypothesis. Journal of Biogeography,38,1546-1556.https://doi.org/10.1111/j.1365-2699. 2011.02512.x

Vray, S. (2018). Cent ans de déclin des bourdons en Belgique: Influence du climat et de l'occupation du sol. PhD thesis, UMons, 2018, 489 pp.

Vray, S., Rollin, O., Rasmont, P., Dufrêne, M., Michez, D., \& Dendoncker, N. (2019). A century of local changes in bumblebee communities and landscape composition in Belgium. Journal of Insect Conservation, 23, 489-501. https://doi.org/10.1007/s10841-019-00139-9

Wang, J. L. (2004). Sibship reconstruction from genetic data with typing errors. Genetics, 166, 1963-1979. https://doi.org/10.1534/genet ics.166.4.1963

Warzecha, D., Diekötter, T., Wolters, V., \& Jauker, F. (2016). Intraspecific body size increases with habitat fragmentation in wild bee pollinators. Landscape Ecology, 31, 1449-1455. https://doi.org/10.1007/ s10980-016-0349-y
Werner, J., \& Griebeler, E. M. (2011). Reproductive biology and its impact on body size: Comparative analysis of mammalian, avian and dinosaurian reproduction. PLoS ONE, 6, e28442. https://doi.org/10.1371/ journal.pone.0028442

Whiterhorn, P. R., Norvill, G., Gilburn, A., \& Goulson, D. (2018). Larval exposure to the neonicotinoid imidacloprid impacts adult size in the farmland butterfly Pieris brassicae. PeerJ, 6, e4772. https://doi. org/10.7717/peerj.4772

Willmer, P. G., \& Finlayson, K. (2014). Big bees do a Better Job: Intraspecific size variation influences pollination effectiveness. Journal of Pollination Ecology, 14, 244-254. https://doi.org/10.26786/ 1920-7603(2014)22

\section{SUPPORTING INFORMATION}

Additional supporting information may be found online in the Supporting Information section.

How to cite this article: Gérard M, Martinet B, Maebe K, et al. Shift in size of bumblebee queens over the last century. Glob Change Biol. 2019;00:1-11. https://doi.org/10.1111/gcb.14890 